\title{
硅藻の繁殖に關与る海水の生理的性質、特に 垂直的並びに季節的相異に就て
}

\author{
松本近義

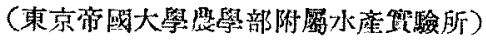

\author{
The Physiological Property of Sea Water Considered from the Effect \\ upon the Growth of Diatom, with Special Reference \\ to its Vertical and Seasonal Change.
}

Tikayosi Matudaina

\section{SYNOPSIS}

In order to study the physiological property of the sea-water, especially its effect on the the growth of diatoms, the present experiment was carried out. Sea-water samples were collected at different depths and on different dates off Sinmaiko, west coast of Tita Peninsula. The sample were enriched with nitrate, phosphate, silicate and iron, and used for culture media of diatoms, artificial light being employed for the illumination. Media prepared with different sea-water samples gave different effect upon the growth of diatoms as shown in Tables 1 and 2, and Fig. 1. The growth of diatoms in media of both the surface and the bottom water was better than in that of the water taken from middle layer (Table. I). The media prepared with water samples taken on different dates at the same place show different grades of effect upon the growth. As the sea-water moves in the sea the water at a certain place changes its property occasionally and it becomes sometimes constal and others oceanic in its nature. Culture media prepared with coastal water gave better growth than those with oceanic water collected thus at the same place but on different dates (Table 2. Fig. 1). The miqueld sea-water enhances the growth of diatoms in the present experiment as in the case of Allen and Nelson (1910), yet the culture with the miquelded sea-water show similarly as in the non-miqueled that the sea-water at different vertical layers has different effect upon the growth of diatoms (Table. 1). This points to the conclusion that the sea-water contains some substance which enhances the growth of diatoms. As both the coastal and the bottom sea-water are alike rich in the organic matter, this substance may enhance the growth of diatoms in the culture media.

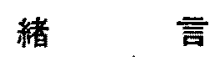

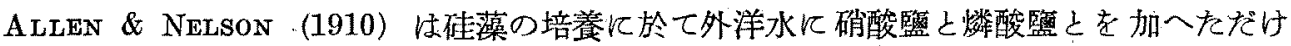
では同藻類は立分敒繁殖し得ないが監化カルシウムと監化鐵を加へるとその發育を大いに促 進すると述べ(1)、海水中に洼硅藻の繁殖を妨げる物質 (inhibitory substances) があると結 論した。との物質は監化カルシウムと監化鐵を加へるととによつて吸着沈洪せられその毒性 を減じ、骨炭儿よつても吸着せられ、又過酸化水素を加へるととによつて分解せられると述 へててる。

其後同氏等 $(1914)^{(2)}$ は更に人工海水を用ひて培盖を行ひ、人工海水にその $1 \%$ 量の自然 
海水を添加すると硅藻の繁殖が促進せられ、その作用は外洋水よりも沿岸水に於て、沿岸水 よりも魯槽の水に於て一層之顯著であり、海水の代りに ulva の抽出液を加へるととによつ ても促進せられる所から見て硅藻の繁殖には或種の有機物が必要であるととを暗示した。

ての等の研究は硅藻の繁殖に閣する海水の生理作用が海水の性質によつて異るととを示す ものであつて海洋の生產力を論ずる上に是非確かめて置かねば度らね問題である。著者はて の點に着目し伊勢灣の海水に就き該生理作用の有無に就て检討を行つた。

\section{方法}

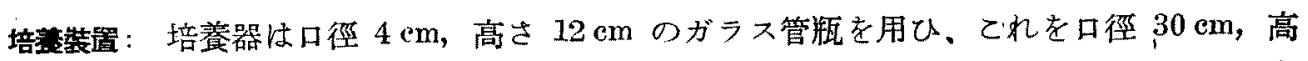
さ $24 \mathrm{~cm}$ のガラス容器內に環形に並べ、゙ラス板を以て覆ひ水槽中に浸し電燈による湭度 の上景を防いだ。光源として $100 \mathrm{~W}$ の電球（東京電氣株式會社製）を用ひてガラス板上距 離 $20 \mathrm{~cm}$ より照射した。日光は悂蔽した。

培恙液の處方及ひ使用法：培食液の基液は次の $\mathrm{A}, \mathrm{B}, \mathrm{C}, \mathrm{D}, \mathrm{E} の 5$ 液である。
A 液
處方
$\mathrm{KNO}_{3}$
$\mathrm{H}_{2} \mathrm{O}$
$20 \cdot 2 \mathrm{~g}$
使用量（海水 $1 \mathrm{~L}$ に對し）
B 液
$\mathrm{Na}_{2} \mathrm{HPO}_{4} \cdot 12 \mathrm{H}_{2} \mathrm{O}$
$\mathrm{CaCl}_{2} \cdot 6 \mathrm{H}_{2} \mathrm{O}$
$\mathrm{H}_{2} \mathrm{O}$
C 液
$\mathrm{FeCl}_{3} \cdot 6 \mathrm{H}_{2} \mathrm{O}$
$\mathrm{H}_{2} \mathrm{O}$

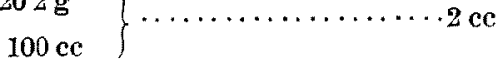
$4 \mathrm{~g}$
$4 \mathrm{~g}$

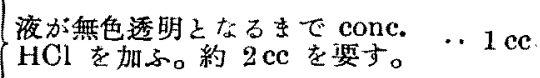 $100 \mathrm{cc}$

$1 \mathrm{~g}$
$100 \mathrm{~g}$
$D$ 液 $\quad(3 / 20) \mathrm{N} \quad \mathrm{NaHCO}_{3}$
................................. $10 \mathrm{cc}$
$\mathrm{E}$ 液 $\mathrm{Na}_{2} \mathrm{SiO}_{3}$ 在蒸溜水儿溶解し $\mathrm{SiO}_{2} 1 \mathrm{~g} / \mathrm{L}$ なる液を得る㥞に調製す。．． $5 \mathrm{cc}$

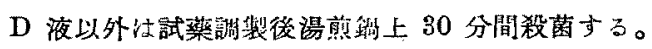

上記の 5 液を下記の如く海水に加へて培養した。

1. 海水 $100 \mathrm{ce}$ 老湯煎鋿上 $95^{\circ} \mathrm{C} に 30$ 分間殺菌し冷却後上記培養基液を各々使用量 だけ加へた。本實驗のすへてはての培垬液て依つた。

2. 海水 $100 \mathrm{cc}$ 儿上記 $\mathrm{A}, \mathrm{B}, \mathrm{C}$ 液を各々使用量を゙り加人て後湯煎鍋上 $95^{\circ} \mathrm{C} に 30$ 分 間殺菌し冷却後 D，E 液を加へを。この海水はミッケル氏海水とは多少異るも作用は變りな く比較のために用ひた。向便宜上本海水はミッケル氏變液と名づけた。

供試海水：佳藻繁殖に對する海水の生理作用の垂直的相異の試驗には伊勢灣横断觀測の際

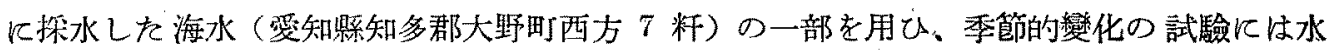
產實驗所前水哚 $3 \mathrm{~m}$ 楾の海水を用ひ探水は大體 4 日每に天候静㮩な日を見て行つた。

供試海水は探水時の水温・監分・燐酸監・佳酸監・亞硝酸監（一部）の分析を行つた。

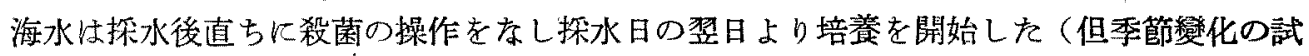
驗を除く。

\section{苗 驗 結 果}

I. 垂直的相異： i) 海水に培養液を加へを場合 現在磷藻の繁殖に不可缺な要素として 


\begin{tabular}{|c|c|c|c|c|c|c|c|c|c|c|}
\hline 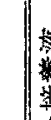 & 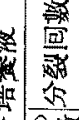 & 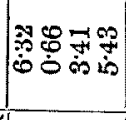 & $1000 \underset{7}{7}$ & $\mid \begin{array}{l}8009 \\
05\end{array}$ & 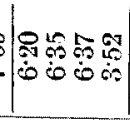 & 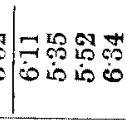 & 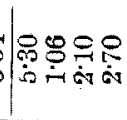 & 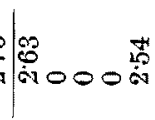 & \multirow{2}{*}{ 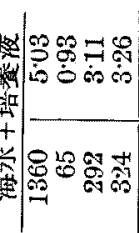 } & 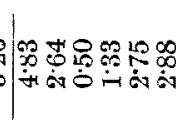 \\
\hline & 要 & 象品 & & 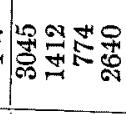 & 过总惑声 & 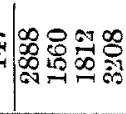 & 象品 & $\int_{\infty} \mathbb{N}^{\infty}=\underset{\mathrm{N}}{\mathrm{S}}$ & & 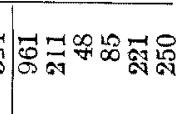 \\
\hline 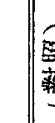 & 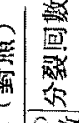 & 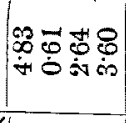 & $000 \frac{1}{0}$ & 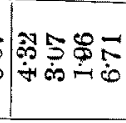 & 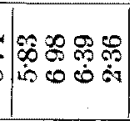 & 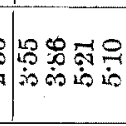 & 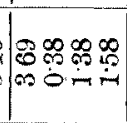 & 40 & 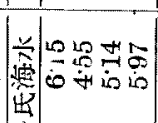 & 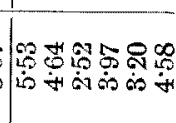 \\
\hline 5 & 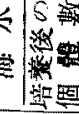 & | & 000 & $\frac{\infty}{80} \stackrel{8}{8}$ & 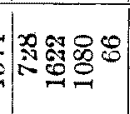 & 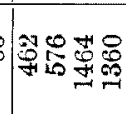 & | & 要 1950 & 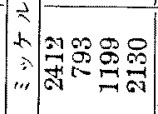 & 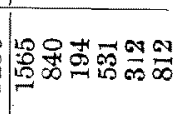 \\
\hline 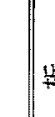 & 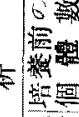 & $\stackrel{9}{\rightarrow}$ & $\theta$ & $\stackrel{9}{\sim}$ & $\stackrel{9}{\rightarrow}$ & 品 & $\infty$ & ณ & 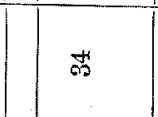 & मे \\
\hline से & 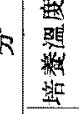 & \%ั & 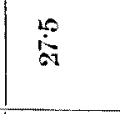 & कू & ڤi & $\stackrel{0}{\dot{\theta}}$ & $\stackrel{\circ}{\text { ڤ్ }}$ & $\stackrel{\circ}{\stackrel{0}{n}}$ & $\stackrel{9}{9}$ & 乌̊요 \\
\hline 45 & 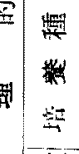 & 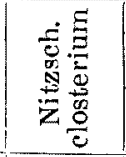 & $s$ & 薄 & " & * & 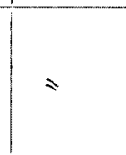 & $=$ & $s$ & $s$ \\
\hline$\div$ & 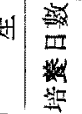 & $n$ & $\sigma$ & סמג & مه & 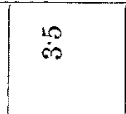 & $\ddot{H}$ & rr & $H$ & + \\
\hline 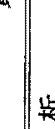 & 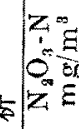 & $0 \stackrel{0}{\circ} \stackrel{2}{\circ}$ & $\sin$ & $0 \begin{array}{ll}20 & 0 \\
0 & 0\end{array}$ & o. & 궁융명 & 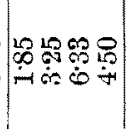 & 11111 & 11111 & 1111111 \\
\hline र & $R$ & 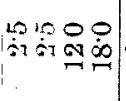 & $00 \stackrel{0}{0} \underset{0}{=}$ & 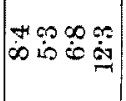 & 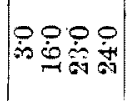 & 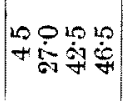 & 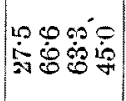 & 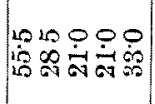 & 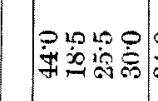 & 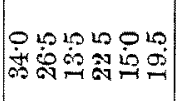 \\
\hline 跑 & 得 & 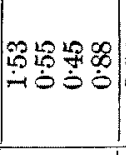 & 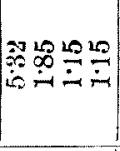 & $\frac{1920}{30}$ & 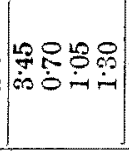 & 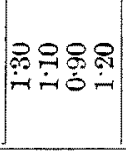 & 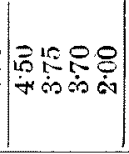 & 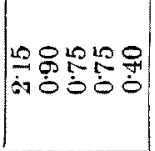 & $\mid \begin{array}{ll}00 \\
0\end{array}$ & 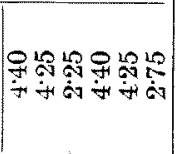 \\
\hline & 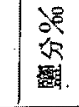 & 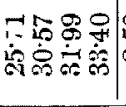 & 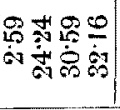 & 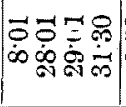 & 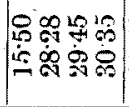 & 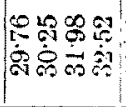 & 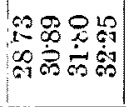 & 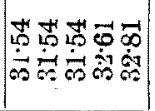 & 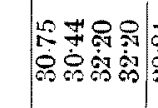 & 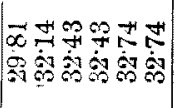 \\
\hline t: & $g$ & $0 \times 9$ 요 & 묘욱요 & ㄴ. 응요 & 010 응요 & $010 \bigcirc 8$ & for & 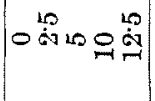 & $\left|\begin{array}{ccc}20 & 10 \\
0 & 0 & 0\end{array}\right|$ & 先 \\
\hline \% & $\begin{array}{l}\square \\
=\end{array}$ & 5 & $\underline{E}$ & 葍 & $\frac{1}{2}$ & $\frac{\alpha}{\infty}$ & 중 & 园 & 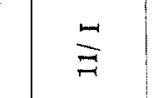 & $\frac{\pi}{9}$ \\
\hline
\end{tabular}




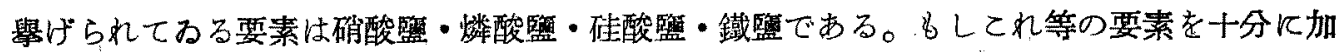
へるならば同一の培荃低件では促進或は阻害物質のない限り同一の繁殖をなす筈である。

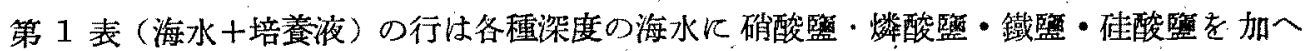
て培養を行つを實驗結果を示す。然るに上揭の培養結果を見る上表層水及底壓水 $(20 \mathrm{~m})$ は

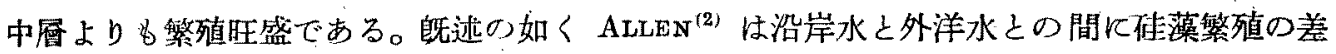
異を認め海水には砫藻繁殖飞對する促進或は阻害物質の存在することを畄示したが著者の實 驗でかっる差異が垂直的にも存在することが明らがになつた。次に化學分析結果と對比して 見ると燐酸監・硝酸監・佳酸監㥉養の際に十分に添加したのであるからてれ等の監類は制限

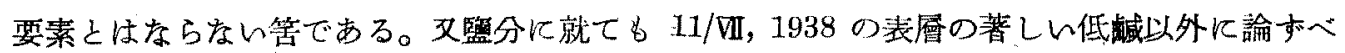
き關係注見られなかつた。監分の變化と硅藻繁殖との關係は既に ALLEN 氏が發表して居り

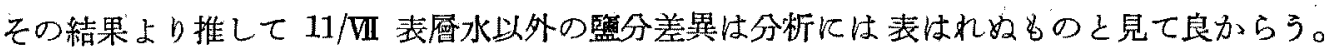
唯こ」に注目すべきは硅藻の繁殖が硅酸監の多少と一致してわる點であるがてれは寧ろ硅酸 監の多少が關係してわるのでなくて（砫酸監を加へてるるから）水塊の相違が硅藻の繁殖に 對して影響してわるものと考入た方が帘當であらう。何んとなれば硅酸監の多少は陸水の影 響或は底質よりの溶出を意味するかららである。本實驗にて化學分析を行つた要素以外に表面 及び底層水の特徵として容易に考へられるのは有㙨物の多い事であるから本實驗传表はれた 海水の生理的性質は ALLEN 等の言ふ如く有機物であらうといふととが铯想せられる。との 點の諭議は次報に謢り本論文は分析に表はれを結果のみを報告する。

ii）對照 對照に表はれた結果は培養液を加へた實驗と比較して表層水以外にはその繁殖

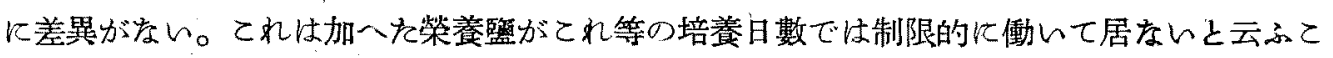
とを示すと見るてとが出來る。唯表層水に於ける繁殖が培養液を加へたものに比して甚た劣 るのは繁殖すべき好條件にあるにも拘ら和策養監が制限的に動いた絬果では無いかと推測さ

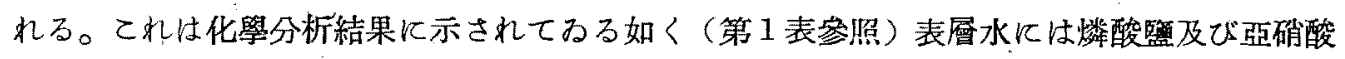
監が甚だ少いてとがその原因であると考へる（硝酸監の分析は行はなかつたが著者の經驗で は亞硝酸監に比例してるるものと思ふ)。しかし如何なる要素艻制限的に働いたかは說明出 來ない。

iii）ミッケふ氏變液を用ひた場合 各深度の海水閒に表はれる生理的性質の差異はミッケ ル氏變液を用ひた場合も同樣であるがミッケル氏變液を用ひた方が普通の培飬液を加へを場 合に比较して各層と夕繁殖が遙に旺盛である(第 1 表)。ての事實は躰に述へた ALLENの 阻害物質の根據であるが本實驗の生理的性質とは別の作用であるが相關したものであるが不 明である。取近 HARVEY (3) (1937) は鐵の曑狀粒子を利用すると述へててるるから培養液を調 㱔する際に鐵監の形態に變化を生するためかもしれない。てれ等の點に就いては尚研究を續 行するつもりである。

II. 季鲩的相異：水塊の相違によつて生理的性質が異ることは上述の結果で大體判明した が页にこの事實を確かめるえめに 18/区 1938〜24/I 1939 の約 5 ケ月間大體 4 日置きに 實驗所前にて探水した海水につんて培善試驗を行つた。培養は『䒺列に分けて行ひ對照とし て前系列の最終月日の\&の一つを入れ順次に培飬し系列 1 の繁殖を 1 として他の系列の更 正储を求めこれを硅蕰の分裂包数に乘じて培責條件による誤差を僅少ならしめた。實驗結果 
第 2 表

\begin{tabular}{|c|c|c|c|c|c|c|c|c|c|c|c|c|c|}
\hline \multirow{2}{*}{$\begin{array}{l}\text { 探水 } \\
\text { 月日 }\end{array}$} & \multirow{2}{*}{$\begin{array}{c}\text { 粱さ } \\
\mathbf{m}\end{array}$} & \multicolumn{4}{|c|}{ 化 學 分 析 } & \multicolumn{8}{|c|}{ 生 理 } \\
\hline & & 장 ${ }^{2}{ }^{\circ} \mathrm{C}$ & 整分前 & $\begin{array}{c}\mathrm{P}_{2} \mathrm{O}_{5} \\
\mathrm{mg} / \mathrm{m} 3\end{array}$ & $\begin{array}{c}\mathrm{SiO}_{2} \\
\mathrm{mg} / \mathrm{L}\end{array}$ & 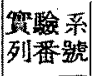 & 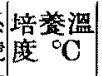 & $\begin{array}{l}\text { 培盖 } \\
\text { 日數 }\end{array}$ & 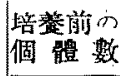 & 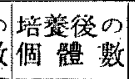 & $\begin{array}{l}\text { 分裂 } \\
\text { 可政 }\end{array}$ & 更正值 & 更正繁包數 \\
\hline $18 / \mathrm{X}$ & $\begin{array}{l}0 \\
2 \cdot 5\end{array}$ & $\begin{array}{l}260 \\
265\end{array}$ & $\begin{array}{l}30 \cdot 81 \\
32 \cdot 25\end{array}$ & $\begin{array}{l}350 \\
20^{\circ} 0\end{array}$ & $\begin{array}{l}4 \cdot 00 \\
3 \cdot 90\end{array}$ & I & 20 & 4 & 12 & $\begin{array}{r}664 \\
0\end{array}$ & $\begin{array}{l}5 \cdot 79 \\
0\end{array}$ & 1 & $\begin{array}{l}5.79 \\
0\end{array}$ \\
\hline $24 / \pi$ & $\begin{array}{l}0 \\
2 \cdot 5\end{array}$ & $\begin{array}{l}23 \cdot 9 \\
24 \cdot 4\end{array}$ & $\begin{array}{l}16 \cdot 93 \\
30 \cdot 35\end{array}$ & $\begin{array}{l}28 \cdot 5 \\
26 \cdot 0\end{array}$ & $\begin{array}{l}1 \cdot 80 \\
2 \cdot 35\end{array}$ & 11 & $"$ & $य$ & "I & $\begin{array}{r}4604 \\
6\end{array}$ & $\begin{array}{l}8558 \\
0\end{array}$ & " & $\begin{array}{l}858 \\
0\end{array}$ \\
\hline $37 / x$ & $\begin{array}{l}0 . \\
25\end{array}$ & $\begin{array}{l}23 \cdot 5 \\
23 \cdot 5\end{array}$ & $\begin{array}{l}29 \cdot 49 \\
30 \cdot 68\end{array}$ & $\begin{array}{l}16.0 \\
21.5\end{array}$ & $\begin{array}{l}3 \cdot 35 \\
275\end{array}$ & 4 & $"$ & $z$ & $"$ & $\begin{array}{r}1976 \\
0\end{array}$ & $\begin{array}{l}7 \cdot 37 \\
0\end{array}$ & $"$ & $\begin{array}{l}7: 37 \\
0\end{array}$ \\
\hline $30 / \mathbf{x}$ & $\begin{array}{l}0 \\
3\end{array}$ & $\begin{array}{l}24.2 \\
24.5\end{array}$ & $\begin{array}{l}28 \cdot 28 \\
28 \cdot 48\end{array}$ & $\begin{array}{l}22 \cdot 5 \\
21 \cdot 5\end{array}$ & $\begin{array}{l}360 \\
255\end{array}$ & $"$ & " & " & " & $\begin{array}{r}1100 \\
520\end{array}$ & $\begin{array}{l}6.52 \\
5.44\end{array}$ & " & $\begin{array}{l}6.53 \\
544\end{array}$ \\
\hline $4 / x$ & $\begin{array}{l}0 \\
3\end{array}$ & $\begin{array}{l}24.0 \\
24.4\end{array}$ & $\begin{array}{l}23 \cdot 86 \\
3046\end{array}$ & $\begin{array}{l}17 \cdot 5 \\
23 \cdot 5\end{array}$ & $\begin{array}{l}339 \\
1.90\end{array}$ & " & " & 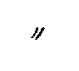 & " & $\begin{array}{l}1892 \\
1260\end{array}$ & $\begin{array}{l}7 \cdot 30 \\
671\end{array}$ & " & $\begin{array}{l}7 \cdot 30 \\
671\end{array}$ \\
\hline $10 / X$ & $\begin{array}{l}0 \\
\mathbf{3}\end{array}$ & $\begin{array}{l}25 \cdot 2 \\
245\end{array}$ & $\begin{array}{l}3169 \\
31.73\end{array}$ & $\begin{array}{l}33 \cdot 0 \\
66 \cdot 6\end{array}$ & $\begin{array}{l}230 \\
215\end{array}$ & " & " & " & $" 1$ & $\begin{array}{l}1092 \\
3756\end{array}$ & $\begin{array}{l}6.51 \\
8.29\end{array}$ & " & $\begin{array}{l}6 \cdot 51 \\
8 \cdot 29\end{array}$ \\
\hline $14 / X$ & $\begin{array}{l}0 \\
3\end{array}$ & $\begin{array}{l}24.0 \\
238\end{array}$ & $\begin{array}{l}24 \cdot 96 \\
29 \cdot 72\end{array}$ & $\begin{array}{l}35.5 \\
66.6\end{array}$ & $\begin{array}{l}460 \\
235\end{array}$ & " & "1 & $"$ & " & $\begin{array}{r}1156 \\
11\end{array}$ & $\begin{array}{l}6.59 \\
0\end{array}$ & $"$ & $\begin{array}{l}659 \\
0 \\
\end{array}$ \\
\hline $18 / x$ & $\begin{array}{l}0 \\
3 \\
\end{array}$ & $\begin{array}{l}19.5 \\
22.5 \\
\end{array}$ & $\begin{array}{l}26 \cdot 29 \\
29 \cdot 18 \\
\end{array}$ & $\begin{array}{l}730 \\
330\end{array}$ & $\begin{array}{r}530 \\
526 \\
\end{array}$ & 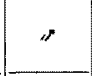 & $"$ & "I & " & $\begin{array}{r}2092 \\
223\end{array}$ & $\begin{array}{l}7 \cdot 44 \\
4 \cdot 2: 2 \\
\end{array}$ & $" 1$ & $\begin{array}{l}7 \cdot 44 \\
4 \cdot 22 \\
\end{array}$ \\
\hline $23 / \mathrm{X}$ & $\begin{array}{l}0 \\
3 \\
\end{array}$ & $\begin{array}{l}22: 0 \\
22 * 4 \\
\end{array}$ & $\begin{array}{l}2999 \\
29 \cdot 16 \\
\end{array}$ & $\begin{array}{l}47 \cdot 5 \\
34 \cdot 5\end{array}$ & $\begin{array}{l}555 \\
571 \\
\end{array}$ & $y$ & $"$ & " & 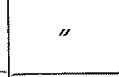 & $\begin{array}{l}3716 \\
1540 \\
\end{array}$ & $\begin{array}{l}8 \cdot 28 \\
7 \cdot 00 \\
\end{array}$ & ' & $\begin{array}{l}8 \cdot 28 \\
7 \cdot 00 \\
\end{array}$ \\
\hline $27 / \mathrm{X}$ & $\begin{array}{l}0 \\
25 \\
\end{array}$ & $\begin{array}{l}22 * 0 \\
22 * 0 \\
\end{array}$ & $\begin{array}{l}2866 \\
3100\end{array}$ & $\begin{array}{l}625 \\
3 * 5\end{array}$ & $\begin{array}{l}4 \cdot 35 \\
3 \cdot 40 \\
\end{array}$ & II & 15 & "1 & 8 & $\begin{array}{r}1730 \\
0\end{array}$ & $\begin{array}{l}776 \\
0\end{array}$ & $1 \cdot 10$ & $\begin{array}{l}854 \\
0\end{array}$ \\
\hline I/XI & $\begin{array}{l}0 \\
25 \\
\end{array}$ & $\begin{array}{l}195 \\
216 \\
\end{array}$ & $\begin{array}{l}12 \cdot t 7 \\
30 \cdot 54\end{array}$ & $\begin{array}{l}22 \cdot 5 \\
38.0\end{array}$ & $\begin{array}{r}14: 29 \\
4: 20 \\
\end{array}$ & $"$ & $"$ & $"$ & " & $\begin{array}{r}236 \\
0 \\
\end{array}$ & $\begin{array}{l}4 \cdot 88 \\
0 \\
\end{array}$ & $"$ & $\begin{array}{l}5: 37 \\
0 \\
\end{array}$ \\
\hline $7 / \mathbf{X}$ & $\begin{array}{l}0 \\
25 \\
\end{array}$ & $\begin{array}{l}19 \cdot 8 \\
22 \cdot 2 \\
\end{array}$ & $\begin{array}{l}29 \cdot 60 \\
31^{\circ} 62 \\
\end{array}$ & $\begin{array}{l}215 \\
380\end{array}$ & $\begin{array}{l}3.50 \\
335 \\
\end{array}$ & "I & "l & $" z$ & " & $\begin{array}{r}472 \\
0\end{array}$ & $\begin{array}{l}5 \cdot 88 \\
0\end{array}$ & $"$ & $\begin{array}{l}647 \\
0 \\
\end{array}$ \\
\hline $10 / X$ & $\begin{array}{l}0 \\
25 \\
\end{array}$ & $\begin{array}{l}196 \\
202\end{array}$ & $\begin{array}{l}2972 \\
2935\end{array}$ & $\begin{array}{l}73 \cdot 5 \\
53 \cdot 2\end{array}$ & $\begin{array}{r}4: 35 \\
425 \\
\end{array}$ & "n & 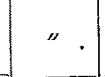 & $1 "$ & $"$ & $\begin{array}{r}1797 \\
11\end{array}$ & $\begin{array}{l}7 \cdot 81 \\
0.54\end{array}$ & $" /$ & $\begin{array}{l}8.59 \\
0.58\end{array}$ \\
\hline $14 / \mathrm{XI}$ & $\begin{array}{l}0 \\
25 \\
\end{array}$ & $\begin{array}{l}142 \\
145 \\
\end{array}$ & $\begin{array}{l}2846 \\
28.62\end{array}$ & $\begin{array}{l}666 \\
750 \\
\end{array}$ & $\begin{array}{l}4 \cdot 25 \\
425 \\
\end{array}$ & נו & "I & " & $\|$ & $\begin{array}{r}937 \\
5\end{array}$ & $\begin{array}{l}687 \\
0 \\
\end{array}$ & " & $\begin{array}{l}7 \cdot 56 \\
0 \\
\end{array}$ \\
\hline $19 / X I$ & $\begin{array}{l}0 \\
2 \cdot 5\end{array}$ & $\begin{array}{l}19.4 \\
203\end{array}$ & $\begin{array}{l}315: \\
32 * 16\end{array}$ & $\begin{array}{l}100 \\
200 \\
\end{array}$ & $\begin{array}{l}395 \\
220 \\
\end{array}$ & " & " & " & 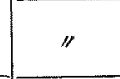 & $\begin{array}{l}5 \\
0\end{array}$ & $\begin{array}{l}0 \\
0 \\
\end{array}$ & $" \prime$ & $\begin{array}{l}0 \\
0 \\
\end{array}$ \\
\hline $23 / \mathrm{X}$ & $\begin{array}{l}0 \\
2 \cdot 5 \\
\end{array}$ & $\begin{array}{l}15^{* 1} \\
14 * 1 \\
\end{array}$ & $\begin{array}{l}2967 \\
30 \cdot 12 \\
\end{array}$ & $\begin{array}{l}290 \\
250 \\
\end{array}$ & $\begin{array}{l}105 \\
030 \\
\end{array}$ & III & 10 & 4 & 6 & $\begin{array}{l}52 \\
18 \\
\end{array}$ & $\begin{array}{l}3 \cdot 17 \\
164 \\
\end{array}$ & 1.01 & $\begin{array}{r}3.20 \\
1.66 \\
\end{array}$ \\
\hline $27 / \mathrm{XI}$ & $\begin{array}{l}0 \\
25 \\
\end{array}$ & $\begin{array}{l}14.0 \\
14.1 \\
\end{array}$ & $\begin{array}{l}29.85 \\
2985\end{array}$ & $\begin{array}{r}30.5 \\
21 \cdot 3 \\
\end{array}$ & $\begin{array}{l}287 \\
190 \\
\end{array}$ & 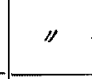 & " & $"$ & "I & $\begin{array}{l}82 \\
26 \\
\end{array}$ & $\begin{array}{l}3.82 \\
2 \cdot 17\end{array}$ & " & $\begin{array}{l}3.86 \\
219 \\
\end{array}$ \\
\hline $29 / X I$ & $\begin{array}{l}0 \\
25 \\
\end{array}$ & $\begin{array}{l}130 \\
152 \\
\end{array}$ & $\begin{array}{l}29.98 \\
3070 \\
\end{array}$ & $\begin{array}{r}185 \\
95 \\
\end{array}$ & $\begin{array}{l}045 \\
055 \\
\end{array}$ & " & " & " & " & $\begin{array}{l}68 \\
31\end{array}$ & $\begin{array}{l}355 \\
242\end{array}$ & $"$ & $\begin{array}{l}3.59 \\
2.44 \\
\end{array}$ \\
\hline $3 /$ XII & $\begin{array}{l}0 \\
2 \cdot 5 \\
\end{array}$ & $\begin{array}{l}125 \\
137\end{array}$ & $\begin{array}{l}2985 \\
30^{\circ} 46\end{array}$ & $\begin{array}{l}8.0 \\
25\end{array}$ & $\begin{array}{l}055 \\
040 \\
\end{array}$ & "I & $"$ & 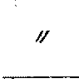 & "I & $\begin{array}{l}77 \\
15 \\
\end{array}$ & $\begin{array}{l}3 \cdot 73 \\
1 \cdot 38 \\
\end{array}$ & $" 1$ & $\begin{array}{l}377 \\
139 \\
\end{array}$ \\
\hline 8/XII & $\begin{array}{l}0 \\
25 \\
\end{array}$ & $\begin{array}{l}11.0 \\
112 \\
\end{array}$ & $\begin{array}{l}3035 \\
30-35 \\
\end{array}$ & $\begin{array}{l}500 \\
500 \\
\end{array}$ & $\begin{array}{l}0.45 \\
035 \\
\end{array}$ & "I & " & 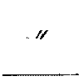 & " & $\begin{array}{r}236 \\
75 \\
\end{array}$ & $\begin{array}{l}5 \cdot 35 \\
3 \cdot 69 \\
\end{array}$ & $"$ & $\begin{array}{l}540 \\
373 \\
\end{array}$ \\
\hline $12 /$ XII & $\begin{array}{l}0 \\
25\end{array}$ & $\begin{array}{l}14 \cdot 2 \\
14 \cdot 2\end{array}$ & $\begin{array}{l}31 \cdot 47 \\
31 \cdot 26\end{array}$ & $\begin{array}{r}475 \\
50\end{array}$ & $\begin{array}{l}0455 \\
065\end{array}$ & $y$ & $" 1$ & $"$ " & $"$ & $\begin{array}{r}228 \\
59\end{array}$ & $\begin{array}{l}530 \\
335\end{array}$ & ij & $\begin{array}{l}5 \cdot 35 \\
3 \cdot 38\end{array}$ \\
\hline
\end{tabular}


第 2 表 $\sigma$ 辚意

\begin{tabular}{|c|c|c|c|c|c|c|c|c|c|c|c|c|c|}
\hline \multirow{2}{*}{$\begin{array}{c}\text { 探水 } \\
\text { 月日 }\end{array}$} & \multirow{2}{*}{$\begin{array}{c}\text { 梁足 } \\
\mathrm{m}\end{array}$} & \multicolumn{4}{|c|}{ 化 學 分 析 } & \multicolumn{8}{|c|}{ 生 理 } \\
\hline & & 水燃 ${ }^{c} \mathrm{C}$ & 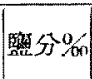 & $\begin{array}{c}\mathrm{P}_{2} \mathrm{O}^{3} \\
\mathrm{~ms} / \mathrm{n}\end{array}$ & $\begin{array}{c}\mathrm{SiO}_{2} \\
\mathrm{mg} / \mathrm{L}\end{array}$ & 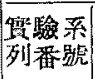 & 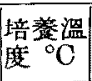 & $\begin{array}{l}\text { 垭蓝 } \\
\text { 日数 }\end{array}$ & $\begin{array}{l}\text { 培荎前 } \infty \\
\text { 個 體 数 }\end{array}$ & 個 體 数 & $\begin{array}{l}\text { 分裂 } \\
\text { 包數 }\end{array}$ & 更正值 & 更正せし \\
\hline $15 /$ XII & $\begin{array}{l}0 \\
25\end{array}$ & $\begin{array}{l}10.5 \\
130\end{array}$ & $\begin{array}{l}50.08 \\
31^{\circ} 04\end{array}$ & $\begin{array}{l}315 \\
175\end{array}$ & $\begin{array}{l}1: 35 \\
0.80\end{array}$ & III & 10 & 4 & 6 & $\begin{array}{r}140 \\
33\end{array}$ & $\begin{array}{l}4.59 \\
2.51\end{array}$ & I.01 & $\begin{array}{l}4.64 \\
254\end{array}$ \\
\hline 18/XII & $\begin{array}{l}0 \\
25\end{array}$ & $\begin{array}{l}120 \\
130\end{array}$ & $\begin{array}{l}30.35 \\
3144\end{array}$ & $\begin{array}{r}150 \\
90\end{array}$ & $\begin{array}{l}0.10 \\
0.60\end{array}$ & 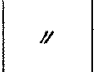 & $"$ & " & $\pi$ & $\begin{array}{r}162 \\
19\end{array}$ & $\begin{array}{l}481 \\
172\end{array}$ & " & $\begin{array}{l}486 \\
174\end{array}$ \\
\hline 20/8II & $\begin{array}{l}0 \\
25\end{array}$ & $\begin{array}{l}105 \\
132\end{array}$ & $\begin{array}{l}30.26 \\
31.04\end{array}$ & $\begin{array}{l}14.0 \\
12.0\end{array}$ & $\begin{array}{l}0.10 \\
085\end{array}$ & " & $"$ & " & $"$ & $\begin{array}{r}215 \\
27\end{array}$ & $\begin{array}{l}521 \\
222\end{array}$ & $y$ & $\begin{array}{l}5 \cdot 26 \\
2 \cdot 24\end{array}$ \\
\hline $26 /$ XII & $\begin{array}{l}0 \\
2 \cdot 5\end{array}$ & $\begin{array}{r}90 \\
120\end{array}$ & $\begin{array}{ll}27 & 11 \\
30 & 70\end{array}$ & $\begin{array}{l}500 \\
49 \cdot 0\end{array}$ & $\begin{array}{l}1.15 \\
080\end{array}$ & $"$ & "I & " & " & $\begin{array}{r}136 \\
20\end{array}$ & $\begin{array}{l}4: 55 \\
1 \cdot 79\end{array}$ & " & $\begin{array}{l}460 \\
181\end{array}$ \\
\hline $6 / \mathrm{I}$ & $\begin{array}{l}0 \\
25\end{array}$ & $\begin{array}{l}7.0 \\
7.3\end{array}$ & $\begin{array}{l}30 \cdot 08 \\
30 \cdot 17\end{array}$ & $\begin{array}{l}55.5 \\
400\end{array}$ & $\begin{array}{l}010 \\
2 \cdot 10\end{array}$ & $"$ & " & " & " & $\begin{array}{r}127 \\
17\end{array}$ & $\begin{array}{l}4.45 \\
1.55\end{array}$ & "I & $\begin{array}{l}4.49 \\
1.57\end{array}$ \\
\hline $10 / I$ & $\begin{array}{l}0 \\
25\end{array}$ & $\begin{array}{l}680 \\
780\end{array}$ & \begin{tabular}{|l|}
30.43 \\
$31 \cdot 26$
\end{tabular} & $\begin{array}{l}25.5 \\
430\end{array}$ & $\begin{array}{l}0.62 \\
0.29\end{array}$ & $\mathbb{N}$ & $" \prime$ & $" 1$ & 34 & $\begin{array}{r}865 \\
57 \\
\end{array}$ & $\begin{array}{l}4 \cdot 67 \\
075 \\
\end{array}$ & 091 & $\begin{array}{l}4 \cdot 25 \\
0 \cdot 68\end{array}$ \\
\hline $14 / I$ & $\begin{array}{l}0 \\
25\end{array}$ & $\begin{array}{l}7 \cdot 30 \\
870\end{array}$ & $\begin{array}{l}3075 \\
31 \cdot 89\end{array}$ & $\begin{array}{l}22 \cdot 5 \\
100\end{array}$ & $\begin{array}{l}0.30 \\
0: 30\end{array}$ & " & " & " & "I & $\begin{array}{r}1049 \\
57\end{array}$ & $\begin{array}{l}4.95 \\
075\end{array}$ & נر & $\begin{array}{l}4.50 \\
0.68\end{array}$ \\
\hline $16 / I$ & $\begin{array}{l}0 \\
25\end{array}$ & $\begin{array}{l}800 \\
89\end{array}$ & \begin{tabular}{|l|}
3126 \\
3180
\end{tabular} & $\begin{array}{l}150 \\
350\end{array}$ & $\begin{array}{l}040 \\
0.23\end{array}$ & " & " & " & "I & $\begin{array}{l}707 \\
6 \pm 3\end{array}$ & $\begin{array}{l}438 \\
419\end{array}$ & $"$ & $\begin{array}{l}3.98 \\
381\end{array}$ \\
\hline $2 \dot{1} / 1$ & $\begin{array}{l}0 \\
25\end{array}$ & $\begin{array}{l}600 \\
8 \cdot 80\end{array}$ & $\begin{array}{l}3086 \\
31.91\end{array}$ & $\begin{array}{l}55 \cdot 5 \\
25 \cdot 0\end{array}$ & $\begin{array}{l}0.20 \\
022\end{array}$ & " & " & " & $"$ & $\begin{array}{r}1111 \\
493\end{array}$ & $\begin{array}{l}503 \\
3.86\end{array}$ & " & $\begin{array}{l}4 \cdot 58 \\
3 \cdot 51\end{array}$ \\
\hline $24 / I$ & $\begin{array}{l}0 \\
2^{*} 5\end{array}$ & $\begin{array}{l}770 \\
900\end{array}$ & $\begin{array}{l}3 y 07 \\
3171\end{array}$ & $\begin{array}{r}95 \\
450\end{array}$ & $\begin{array}{l}032 \\
022\end{array}$ & " & I" & $\not 1$ & $y$ & $\begin{array}{r}1166 \\
100\end{array}$ & $\begin{array}{l}5 \cdot 10 \\
1.56\end{array}$ & " & $\begin{array}{l}4^{*} 64 \\
1^{*} 42\end{array}$ \\
\hline
\end{tabular}

は第 2 表及第 1 圖に示す。繁殖は前實 驗結果上同樣儿上下兩水の混合のない限 り殆に゙常江表面水に於て繁殖が盛儿であ る。しか８日時的變化は不規則なるので なく第 1 圆に示す如く連續的な變化を 示し水塊の移動之明らかに一致するとと が窥はれる。即ち 19/XI を境界として 繁殖の狀態㵔しい差があるが水質的に 水溫 - 監分・砫酸監にて制万如く大ん に異つてるる。撸言すれば河水の影響あ る海水（沿岸水）に培養液を加へて住藻 を培養したものは然らざる海水に培養液 を加へて培養した多のよりも繁殖が良い といふ事である。

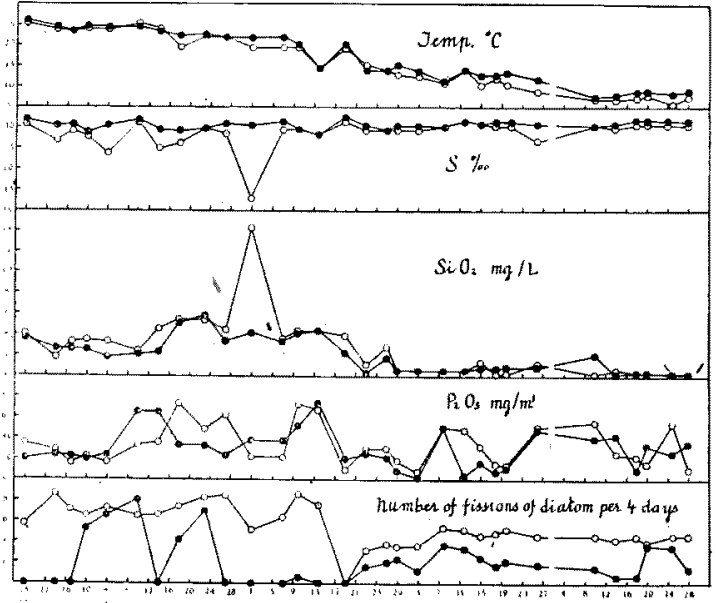

第 1 圆

最後に本實驗に於て注目寸べ事は柔列の始めの女のと終りの安の上は探水の月日に於て 約 1 ケ月の差罢あり，その間始めの海水は暗所に放置して置いたにも拘ら和實驗結果から 見ると海水の生理的性質に變化を生に゙を様子が見られ始といふ事である。てれから見て該生 理的性質はかなり安定なものと言人る。 


\section{結語}

ÁLLEN は人工海水を用ひて住莯を培養する際にその $1 \%$ 亿當る自然海水の添加を必要で あるとなし、その效力に於て添加海水が沿岸水の場合上外洋水の場合とではその間に差異あ

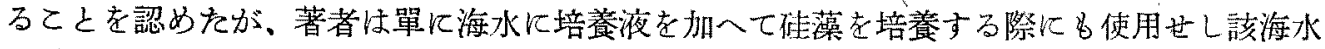
間にその繁殖に對する生理的性質に差異することを認め、種及の深度の海水につき實驗した 所上層の海水及ざ底層の海水は中盧の海水よりる繁殖盛んであることが制明した。メこの海 水の性質は水塊の性質によつて買ることが明らかに症つた。即ち沿岸性の海水は外洋性の海 水より名硅藻の繁殖が良好であつた。これ等の榙事實及 ALLEN の研究結果より推して硅藻 の繁殖に關する海水の生理的性質は海水中に含まれる有機物であらうといふ愔示を得、更に 研究を續行した。この研究結果は後報に褧ること〉する。

ミッケル氏變液が海水に單に培養液を加へをものよりる繁殖盛んなることはALLEN 等の 得を結果と全く同一であるがその繁殖促進作用はミッケル氏海水老作る際に生市る燐酸鐵の

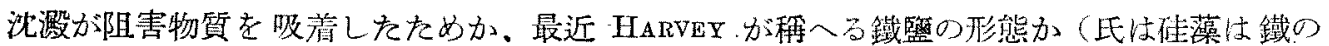
翏狀粒子を利用する事實を述べてみる(3)）更に研究を要する點である。

尚本研究は帝國學土院より研究費補助を受けて行つた研究の一部で同院代對し深く謝意を 表する次第である。又御校閱を賜つを雨宮育作敎授に哚謝する。

\section{文獻}

(1) Allen and NELson: On the artificial culture of marine plankton organisms. Quart. Journ. Micro. Sci., 55, 1910.

(2) AlleN, E. J.: On the culture of the plankton diatom Thalassiosira gravida, Cleve, in artificial sea water. Jour. Mar. Biol. Assoc., 10, 1914.

(3) Harvey H. W.: The supply of iron to diatoms. Journ. Mar. Biol. Assoc., 22 (1), 1937. 